\title{
A ATUAÇÃO DO PLANFOR NO COMBATE À POBREZA EM MACEIÓ
}

\section{THE ACTING OF THE PLANFOR IN THE COMBAT TO THE POVERTY IN MACEIÓ}

\author{
Laura Cristina Vieira Pizzi ${ }^{1}$ \\ Izabella da Silva Vieira \\ Maryanna Chelly Barbosa Melo
}

\section{Resumo}

Esta pesquisa teve como objetivo examinar as conseqüências dos cursos de qualificação profissional básica oferecidos pelo PLANFOR em Maceió/AL, considerando a eficácia em sua aplicação, verificando de que forma os alunos absorveram e avaliaram os conteúdos transmitidos durante o curso, fazendo o levantamento do perfil socioeconômico dos alunos egressos, avaliando o impacto que o curso de qualificação profissional causou na vida produtiva das pessoas que participaram do programa. Foi discutida ainda a sua vinculação aos novos conceitos de formação, qualificação e competência, de que forma está engajado as novas exigências do novo modelo de produção. Esta pesquisa é de cunho qualitativo, e a abordagem metodológica adotada foi a Análise de Conteúdo. A pesquisa foi realizada através de entrevistas com alunos egressos dos cursos e através de análise documental. Entendemos que o PLANFOR, não atingiu seus objetivos, já que a maioria dos entrevistados se encontrava fora do mercado de trabalho. Os cursos também não conseguiram elevar significativamente o nível da renda de seus egressos. Verificamos que os conteúdos ensinados de forma transversal, de cunho mais social, foram pouco absorvidos pelos ex-alunos, mas aqueles conhecimentos diretamente ligados à profissão ainda estavam bem presentes na memória dos egressos.

Palavras-chave: Qualificação profissional - pobreza - políticas públicas

\section{Abstract}

The main goal of our research was examining the consequences of basic professional education courses offered by PLANFOR at the city of Maceió/AL, considering its efficacy, verifying the ways students learned and evaluated the knowledge they learned during the courses, taking the socioeconomic profile of the students, evaluating the impact of this kind of courses on the professional and productive life of people who participated on them. Was discussed either the links between the courses and the new concepts like education, basic skills, and competences, and the ways they are engaged on the demands of the new production model. The research is qualitative and the methodology is Content Analysis. To do the research we used interviews with students who had already 
finished the courses and documental analysis. We understand that PLANFOR did not achieve its main goal, considering that the majority of the students are off of the labor market. The courses also did not improve the domestic budget of the students. We verified that the transversal contents, with social approach, was poorly remembered by the students, but the contents related to the profession, was vivid on their memory.

Key Words: Professional education - poverty - public policy

Este trabalho é o resultado de uma pesquisa desenvolvida nos anos de 2004 e 2005 em Maceió/AL, que visou analisar o PLANFOR (Plano Nacional de Educação Profissional) e seus impactos em Maceió, enquanto uma política educacional que tem em vista a inserção de indivíduos no mercado de trabalho. $\mathrm{O}$ PLANFOR foi uma política de qualificação profissional desenvolvida entre os anos de 1995 até 2002, na gestão do presidente Fernando Henrique Cardoso².

O objetivo do PLANFOR foi fornecer cursos profissionalizantes como forma de inserir trabalhadores desempregados no mercado de trabalho, e, desta forma, contribuir para a elevação da renda e da qualidade de vida dos cidadãos. Foi um programa de qualificação e requalificação profissional básica, promovido pelo Ministério do Trabalho brasileiro e financiada pelo Fundo de Amparo ao Trabalhador (FAT).

O público alvo deste programa são os trabalhadores que perderam seus postos de trabalho em decorrência das transformações tecnológicas e organizacionais ocorridas na produção, a partir dos anos 90 no Brasil. Também fazem parte deste programa os trabalhadores empregados de baixa-renda. A idéia é favorecer, através da qualificação/requalificação profissional, a inserção de setores considerados desqualificados e pobres da força de trabalho no mercado de trabalho local, portanto com dificuldades de competir neste mercado em condições educacionais melhores.

Esta pesquisa é de cunho qualitativo, e a abordagem metodológica adotada foi a Análise de Conteúdo, que segundo Triviños (1987), é um conjunto de técnicas de análise das comunicações que, por procedimentos sistemáticos e objetivos de descrição do conteúdo das mensagens, visa obter indicadores 
qualitativos ou quantitativos que permitam a inferência, e assim levantam como resultado o estudo dos dados que apresenta a comunicação.

\section{Pobreza}

Segundo Schwartzman (2004), até 30 anos atrás, as questões que ocupavam os cientistas sociais eram relacionadas ao desenvolvimento econômico, a modernização, a democracia e a mobilidade social. Hoje os temas dominantes são a pobreza e a exclusão social. Não que esses temas não existissem no passado, mas eram vistos como uma decorrência de problemas, deficiências na ordem econômica, política e social, que seriam resolvidas e superadas à medida que estes fossem sendo equacionados.

As causas da pobreza, em geral apontadas como estruturais pela literatura, são as seguintes: a exploração do trabalho pelo capital; o poder das elites que parasitavam o trabalho alheio e saqueavam os recursos públicos; e a alienação de pessoas, criada pelo sistema de exploração, que as impedia de ter consciência dos próprios problemas e necessidades.

A solução a curto prazo para os problemas da pobreza no Brasil historicamente não têm tido sucesso. A falta de vontade política e compromisso com os valores da igualdade social e dos direitos humanos também têm sido apontados como entraves, bem como uma política econômica adequada, um setor público eficiente, competente e responsável no uso dos recursos que recebe a sociedade e políticas específicas nas áreas da educação, da saúde, do trabalho, da proteção à infância e do combate à discriminação social, entre outras.

O Brasil convive historicamente com grandes desigualdades sociais e níveis inaceitáveis de miséria absoluta. O próprio progresso material das ultimas décadas contribuiu para a emergência de novos problemas sociais, que se somam às deficiências estruturais que persistem sem solução, após várias décadas de desenvolvimento.

Sem diminuir a importância dos problemas de pobreza e de privação que afetam vários segmentos sociais, segundo Abranches (1989), o Brasil esta longe de uma situação de indigência e miserabilidade generalizada. O Brasil não 
tem problemas de falta de alimento, ou desabastecimento, que pudessem justificar políticas de envio de alimentos. O que falta é, simplesmente, dinheiro, o que justifica a importância das propostas de renda mínima. Existem razões para se preocupar com as situações de pobreza extrema e desenvolver políticas assistências e compensatórias que possam socorrer as pessoas em situação de maior privação. Esta proposta assistencialista está longe se ser consensual, mas podemos observar que tem sido a marca das políticas de combate à pobreza no Brasil

\section{Políticas públicas de combate à pobreza}

O avanço da produção e organização social capitalista sempre vem acompanhado de questões sociais complexas e intensas. A proletarização crescente da população, que tem no salário o elemento central da sua sobrevivência; a concentração da população em centros urbanos, que rompe o vinculo imediato com a natureza como meio de subsistência e o desaparecimento das formas tradicionais de proteção social, fazem aparecer a insegurança social e aumentam a pobreza.

O avanço do capitalismo também fomenta as lutas pela garantia da satisfação das necessidades sociais; a alimentação, a habitação, a saúde e a educação. Dessa forma, a questão social transforma-se em fato público, e as sugestões para selecioná-la constituem-se em elementos definidores de projetos e partidos políticos.

Segundo Laurell (1997), a tradução concreta das colocações feitas a esse respeito são as políticas sociais, ou seja, o conjunto de medidas e instituições que tem por objetivo o bem-estar e os serviços sociais.

A política de combate a pobreza, estruturalmente enraizada, tem natureza distinta. Seu objetivo é a destruição da pobreza, incorporando os excluídos nos circuitos regulares da vida social e compensando as principais carências que põem em risco a sobrevivência e a sanidade física, emocional e mental dessas pessoas. 
Segundo Abranches (1989), no Brasil, convivem duas formas de pobreza. Aquela de natureza estrutural, mais persistente, associada ao desdobramento histórico do nosso padrão de desenvolvimento, e a pobreza cíclica, que se agravou com a crise do desemprego, a queda da renda, sua concentração crescente e a aceleração inflacionaria.

Laurell (1997) diz que, apesar das interações e correlações entre pobreza e desigualdade, estes dois fenômenos constituem objeto de políticas distintas e diferenciadas. Combater a miséria e reduzir a desigualdade são objetivos diferentes que requerem estratégias de ação diversas e implicam decisões e processos políticos também diferenciados.

As políticas voltadas para a redução da destituição requerem ações em três linhas principais: em primeiro lugar, medidas de reorientação, no médio e longo prazo, do próprio padrão de desenvolvimento, de modo a corrigir processos estruturais que estão na raiz do estoque permanente de pobreza. Essas correções têm por objetivo modificar o padrão de produção e consumo e alterar a estrutura de oportunidades da sociedade, de modo a assegurar recursos de acesso e mobilidade aos segmentos destituídos.

Em segundo lugar, são necessárias medidas de curto e médio prazo, que redirecionam o processo econômico no sentido da ampliação das condições de acesso aos bens essenciais e oportunidades de inserção no mercado de trabalho, antes mesmo da consolidação de mudanças mais estruturais. Nessa dimensão, a ação do estado é fundamental, pois os mecanismos de mercado serão insuficientes, diante das limitações estruturais que ainda persistem.

Para a autora, programas dessa natureza requerem decisões políticas cruciais em várias áreas. Não basta definir setorialmente os programas. É preciso definir o conjunto da ação governamental para esse objetivo. Para tanto certas decisões econômicas devem ser batizadas pela política social. Alem disso, envolvem importantes mudanças nos padrões de financiamento do setor publico, nas prioridades orçamentais e no processo de alocação de recursos.

Segundo Schwartzman (2004), não há solução em curto prazo para os problemas da pobreza do Brasil. Para que a pobreza seja vencida, são 
necessárias; vontades políticas e compromisso com os valores de igualdade social e dos direitos humanos; uma política econômica que gere os recursos que recebe da sociedade; além de políticas especificas nas áreas de educação, da saúde, do trabalho, da proteção à infância e do combate a discriminação social, entre outras. A construção de uma sociedade competente, responsável, comprometida com os valores de equidade e justiça social, e que não caia na tentação fácil do populismo e do messianismo político, e uma tarefa de longo prazo.

\section{História da educação profissional}

Segundo Manfredi (2002), desde os tempos remotos o trabalho é uma atividade social central para garantir a sobrevivência de homens e mulheres e para a organização e o funcionamento da sociedade. Portanto, sempre esteve ligada à formação dos trabalhadores e dos pobres como forma de inseri-los no mercado de trabalho.

$\mathrm{Na}$ sociedade primitiva a base da economia era a coleta, a pesca, a agricultura rudimentar. A divisão do trabalho se dava de acordo com o sexo e a idade. Na sociedade agrícola, continuam as mesmas tarefas, mas a agricultura se desenvolve, aperfeiçoa os equipamentos e assim começam a surgir as cidades, havendo uma complexidade na divisão do trabalho. Surgem as classes sociais, as corporações de ofício e as primeiras noções de profissão.

Ao longo do tempo o trabalho passa de produção de subsistência à produção para a troca, sendo agora um autônomo assalariado. Surgem as indústrias, exigindo profissionais com novos conhecimentos e habilidades, e assim foram diminuindo os postos de trabalho, causando o desemprego, pois o homem foi gradativamente sendo substituído pela máquina.

Nas sociedades industriais, os assalariados exercem diferentes funções, trabalham na indústria, no comércio, na agricultura e outros serviços. No Brasil, a população economicamente ativa passou de 42\% (1940) para 62,8\% (1980). De 1989 a 1995 diminui as taxas de emprego informal (13,6\% para $27,3 \%)$. No Brasil, há grande concentração nas ocupações profissionais inferiores e baixa concentração nas ocupações intermediárias e superiores. 
A escola foi criada para preparar grupo de pessoas para o exercício do comando, do poder e da direção social. Durante séculos a única escola para as classes populares era o domínio de técnicas, métodos e rotinas das tarefas dos diferentes ofícios. Com expansão do capitalismo industrial criou-se a necessidade da universalização da escola para inserção no mundo do trabalho.

\section{Educação e modos de produção}

Ao longo da história a escola tem se mostrado intimamente ligada às relações do modo de produção, isso porque ela é considerada uma das instituições básicas para a produção e reprodução da força de trabalho (SANTOS, 1997), refletindo o momento que a sociedade está vivendo e atendendo as necessidades do mercado de trabalho.

No contexto das novas tecnologias, a educação básica surge com força, "mais que um mero requisito de seleção, como era o diploma, passa a ser condição de acumulação, condição de "qualificação" da classe trabalhadora" (PIZZI, 2001, p. 27), sendo considerada como um dos aspectos mais importantes na valorização do capital.

A demanda por um novo modelo de produção exige trabalhadores que possuam as mais diversas habilidades, que vão desde a criatividade, eficácia grupal, raciocínio e outras categorias que possibilitem um profissional polivalente que incidam numa formação politécnica, pois além de saber o que faz, precisa também ser sujeito crítico e pensante, já que a instabilidade do mercado obriga a aquisição de um conhecimento vasto para perpassar de uma profissão à outra. Acabando com o conhecimento especializado e favorecendo a uma flexibilidade.

A aquisição destas habilidades representa um avanço a classe trabalhadora, mas que por traz deste discurso existe, um favorecimento do individualismo, da competição e da ambição. Neste novo modo de produção capitalista o individuo vale como força de trabalho e não como ser humano integral, portanto, toda preocupação que perpasse a formação desse trabalhador, não está voltada para seu desenvolvimento social, mas para a produtividade e 
adequação a melhor forma possível de produção de mercadorias, dotando a esse indivíduo o valor das coisas que ele produz.

\section{Da qualificação à competência:'}

No mundo capitalista os trabalhadores precisam se adaptar às exigências do mercado de trabalho, assim, se moldam as suas categorias, que também sofrem mutações com o tempo e com as novas relações e modificações que se estabelecem nos modos de produção. O famoso exército industrial de reserva serve como regulador direto para coagir sem poder contestar, o trabalhador aceita as condições impostas pelo capital.

Nascido do pós-guerra o conceito de qualificação, surge como uma formalização do que foi adquirido pelos movimentos sociais antecedentes.

Qualificação é um conceito ligado ao processo de formação, a aquisição de diploma e domínio de conceitos e de determinados níveis de conhecimento, evidenciando a existência de práticas educativas que legitimam o trabalho "qualificado". O diploma seria então a garantia de emprego, de status e possivelmente uma maior remuneração e uma hierarquização na função.

Em meados dos anos 80 a noção de competência passa a substituir gradativamente o termo qualificação. Com as novas formas de relações sociais provocadas pela substituição do modelo Taylor-Fordista, pelo modelo Japonês, surgiram novas formas de inserção dos indivíduos no mercado de trabalho, um novo perfil se impõe à formação do trabalhador, afetando o modelo pedagógico escolar até então estabelecido. O discurso das competências e da empregabilidade tem servido apenas para colocar sobre o trabalhador toda a responsabilidade sobre a sua formação e inserção no mercado de trabalho.

Exige-se um novo perfil profissional, pautado nos aspectos de flexibilidade (para mudar de função, ou até mesmo de empresa), polivalência, autonomia, criatividade, iniciativa, saber resolver imprevistos. Agora só o diploma/ conhecimento não é o suficiente, é preciso que o trabalhador detenha uma constante capacidade de adaptação as mais variadas situações, precisa utilizar tudo o que sabe, adequando e até mesmo transformando em novos 
conhecimentos. Os cursos de formação continuada a partir da década de 90 passaram a ser altamente incentivados pelas empresas, buscando uma constante aprendizagem do funcionário, para que o mesmo não esteja à margem das rápidas transformações do mundo do trabalho.

Essas transformações se traduzem num processo extremamente competitivo, enfraquecendo a solidariedade e impossibilitando a união para os movimentos trabalhistas.

As novas exigências nos mostram que ter formação e estar apto a exercer determinada função não é mais suficiente para garantia de um emprego, o sujeito precisa definir-se como um funcionário diferenciado, ou seja, a formação é importante, pois torna o individuo "competente", mas não é suficiente, pois o mesmo deve possuir capacidade de realizar as habilidades adquiridas em sua formação, mas deve também ser capaz de transportar seus conhecimentos para outras atividades e ter condições de buscar inovações - aprender-a-aprenderporque precisa a todo instante estar se qualificando, se modificando e se moldando conforme as necessidades do mercado.

Segundo Desaulniers "as noções de formação, qualificação e competência apresentam vários elementos de articulação entre si, mas isto não permite que se utilizem tais termos enquanto sinônimos". (1993, p.102)

\section{0 planfor como um programa profissionalizante de combate à pobreza}

Plano Nacional de Qualificação do Trabalhador, iniciado em 1995, foi um dos mecanismos da Política Pública de Trabalho e Renda (PPTR), no âmbito do FAT - Fundo de Amparo ao Trabalhador. O FAT patrocina diversos tipos de ações destinadas a gerar trabalho e renda, melhorar as condições de acesso ou permanência no mercado de trabalho e proteger a pessoa desempregada, como por exemplo: o seguro-desemprego, a intermediação de mão de obra, o pagamento de abonos salariais, os investimentos produtivos, o crédito popular, a informação sobre o mercado de trabalho e a qualificação profissional - esta por meio do PLANFOR. 
O objetivo do PLANFOR foi garantir uma oferta de educação profissional (EP) permanente, contribuindo para: reduzir o desemprego e 0 subemprego da população economicamente ativa (PEA), combater a pobreza e a desigualdade social e elevar a produtividade, a qualidade e a competitividade do setor produtivo.

O PLANFOR surge com 0 objetivo ambicioso de promover a qualificação profissional como direito do trabalhador e componente básico do desenvolvimento sustentado, com eqüidade social. A sua meta global foi construir, a médio e longo prazo, oferta de EP suficiente para qualificar, a cada ano, pelo menos $20 \%$ da PEA.

\subsection{Público}

Embora tenha como foco geral a PEA, o PLANFOR opera, para fins da aplicação dos recursos do FAT, com duas definições de público-alvo: grupos vulneráveis e outros que sejam vitais para o desenvolvimento sustentado. No primeiro caso - grupos vulneráveis - o PLANFOR garante pelo menos $80 \%$ dos recursos e $90 \%$ das vagas - para quatro categorias: pessoas desocupadas; pessoas em risco de desocupação permanente ou conjuntural; empreendedores/as urbanos/rurais; pessoas autônomas, cooperadas, autogeridas (v. quadro a seguir). A focalização desses grupos é importante para orientar maior integração entre os mecanismos do FAT, em especial da qualificação profissional com a intermediação, o crédito popular e o seguro desemprego.

Além desses quatro grupos, o PLANFOR reserva até $10 \%$ das vagas e $16 \%$ dos recursos para qualificar outros grupos definidos com base em prioridades locais/regionais e a qualificação de membros gestores. 
PLANFOR: público alvo prioritário

\begin{tabular}{|c|c|}
\hline żrupos & \\
\hline $\begin{array}{l}\text { 'essoas } \\
\text { ocupadas }\end{array}$ & $\begin{array}{llll}\text { Desempregadas } & \text { com } & \text { seguro } & \text { desemprego; } \\
\text {.Desempregadas } & \text { sem } & \text { seguro } & \text { desemprego; } \\
\text {.Cadastradas no SINE e Agências de Trabalho de sindicatos; } \\
\text {.Jovens buscando } 1^{\circ} \text { trabalho; }\end{array}$ \\
\hline $\begin{array}{l}\text { Pessoas ocupadas, } \\
\text { desocupação } \\
\text { dermanente ou } \\
\text { conjuntural }\end{array}$ & $\begin{array}{l}\text { Empregados/as em setores que estão passando por } \\
\text { modernização ou reestruturação, enxugando quadros e/ou } \\
\text { exigindo novos perfis profissionais. Ex.: bancos, portos, indústrias, } \\
\text { administração pública; } \\
\text { Trabalhadores/as em atividades sujeitas à instabilidade por fatores } \\
\text { como clima, restrição legal, ciclo econômico. Ex.: pescadores/as } \\
\text { em períodos de defeso; agricultores/as em atividades sujeitas a } \\
\text { flagelos do clima (seca, geada, inundação) e a conjunturas do } \\
\text { mercado internacional (crises financeiras, medidas de } \\
\text { protecionismo); } \\
\text { Trabalhadores/as domésticos/as; }\end{array}$ \\
\hline $\begin{array}{l}\text { 3. Empreendedores } \\
\text { (que já têm ou querem } \\
\text { iniciar micro e } \\
\text { pequenos negócios) }\end{array}$ & $\begin{array}{l}\text { Beneficiários/as do crédito popular (Proger, Pronaf); } \\
\text { Beneficiários/as do Brasil Empreendedor } \\
\text { Agricultores/as familiares } \\
\text { Assentados/as rurais } \\
\text { sócios/as ou donos/as de pequenos negócios urbanos }\end{array}$ \\
\hline $\begin{array}{l}\text { Associadas } \\
\text { cooperadas } \\
\text { auto geridas }\end{array}$ & $\begin{array}{l}\text { Trabalhando por conta própria; } \\
\text { Participantes de associações, cooperativas, grupos de produtores } \\
\text { que assumem a gestão de empresas, para garantir sua } \\
\text { continuidade e os empregos }\end{array}$ \\
\hline
\end{tabular}

Disponível em: <http://www.mtb.gov.br>.

\subsection{O planfor e as competências}

O PLANFOR tem como objetivo reduzir o desemprego e o subemprego da população economicamente ativa, combater a pobreza e a desigualdade social, elevar a produtividade, a qualidade e a competitividade do setor produtivo, para 
tanto, segundo o Guia do PLANFOR, os conteúdos desenvolvidos nos cursos de qualificação profissional deve atender a três pólos:

\begin{abstract}
*Habilidades básicas = competências, atitudes e conhecimentos essenciais para a formação do "cidadão produtivo", como comunicação verbal e escrita, leitura e compreensão de textos, raciocínio, saúde e segurança no trabalho, preservação ambiental, direitos humanos, informação e orientação profissional e outros eventuais requisitos para demais habilidades;

${ }^{*}$ Habilidade específica $=$ competências e conhecimentos relativos a processos, métodos, técnicas, normas, regulamentos, matérias, equipamentos e outros conteúdos próprios das ocupações/setores.

*Habilidades de gestão = competências, atitudes e conhecimentos para formar, manter e melhorar o desempenho de micro e pequenos empreendimentos, rurais ou urbanos, bem como gerenciar o próprio trabalho, como autônomo, cooperado, associado, empregado ou auto gerido. (PLANFOR, 2001, p. 27)
\end{abstract}

Possuindo assim,em seu discurso, a apreensão dos novos conceitos que circulam no mercado de trabalho, como competitividade, gestão, qualidade e sobretudo a questão da competência, que sem elas o trabalhador certamente não se enquadraria num mundo que esta cada vez mais excludente.

\title{
6.3 Resultados:
}

$\mathrm{Na}$ Secretaria Estadual do trabalho de Alagoas recolhemos uma listagem de alunos egressos dos cursos oferecidos pelo PLANFOR, por diversas entidades, nos anos de 2001 e 2002.

- Os cursos foram: Informática Básica, Camareira, Corte e costura, Garçom, Preparação para Primeiro Emprego em Vendas, Valorização do servidor público, Porteiro de Edifício, Industrialização de doces e Intérprete de LIBRAS;

- Foi realizado um total de 23 entrevistas, dentre essas foram 16 do sexo feminino e 7 do sexo masculino;

- A faixa etária dos alunos egressos situava-se entre 15 e 50 anos;

- Nível escolar: 5 com Ensino Fundamental incompleto, 2 com Fundamental completo, 4 com Ensino Médio incompleto, 9 com Ensino Médio completo e 3 com Ensino Superior incompleto;

- Renda: $\mathrm{R} \$ 150,00$ a $\mathrm{R} \$ 1.200,00$ reais; 
- Dentre esses, 8 estavam trabalhando e 15 se encontravam desempregados;

- Entre os desempregados, 2 eram homens e 13 eram mulheres.

- Os conhecimentos que os alunos egressos mais lembram do curso que fizeram se referem às técnicas relacionadas ao trabalho, seguidos dos conhecimentos referentes ao comportamento, à aparência. A auto- estima é também algo que os alunos recordam, sendo que os conhecimentos de cunho social, no que diz respeito a ecologia e sindicato, que estão inclusive dentro da proposta do PLANFOR, não são lembrados pela grande maioria do quadro dos entrevistados;

- Dos entrevistados $80 \%$ confirmaram que houve aula prática e apenas $17 \%$ que não houve;

- Apenas um dos entrevistados afirmou a existência de estágio, encaminhado pelo curso.

- Não houve nenhuma insatisfação com relação aos professores;

- Todos gostaram do curso;

- Os alunos sugeriram para melhoria do curso: encaminhamento para o mercado de trabalho, melhor local, mais vagas, mais aulas práticas, encaminhamento para estágio e carga-horária maior.

\section{Considerações finais}

Como o objetivo desta pesquisa examinar as conseqüências dos cursos de qualificação profissional oferecidos pelo PLANFOR na cidade de Maceió, podemos afirmar que a maioria dos entrevistados se enquadra plenamente no público-alvo do PLANFOR, pois faz parte da camada da população pobre, desempregado ou em risco de desemprego. Mas, quatro dos entrevistados apresentaram uma condição de vida que indicavam não se encaixar diretamente no perfil, pois têm boas condições econômicas (ou seja, uma renda mensal de 4 salários mínimos ou mais). Quanto aos que estão trabalhando, apenas quatro conseguiram emprego na área do curso que fizeram no PLANFOR.

Observamos ainda que o público-alvo que majoritariamente procurou os cursos investigados oferecidos pelo PLANFOR foi o feminino. E que este mesmo 
público feminino é o que se encontrava quase na totalidade desempregado no período da pesquisa.

Também podemos afirmar que a proposta do PLANFOR, de inserir trabalhadores no mercado de trabalho, não foi atinginda de forma satisfatória, já que a maioria dos entrevistados se encontrava fora do mercado, mesmo depois de realizarem os cursos. Os cursos também não conseguiram elevar significativamente o nível da renda de seus egressos ou mesmo tirá-los da condição de risco social em que se encontravam antes de serem concluídos (pois sua renda continuava, em média muito baixa).

Foi possível averiguar que a auto-estima é bastante trabalhada nos cursos, e que os alunos conseguem lembrar dos conhecimentos específicos do curso, os relacionados diretamente à atividade profissional, mesmo aqueles que não estão trabalhando na área, mas os conhecimentos sociais (sindicato e ecologia) não parecem ser valorizados pelos egressos.

A falta de estágio é uma das grandes falhas, já que o mercado de trabalho hoje não só exige uma qualificação, é necessário também que o trabalhador possua experiência no ramo em que pretende atuar.

Além disso, segundo os egressos, a carga-horária mostra-se insuficiente para atender as necessidades do público alvo, onde no Guia do Planfor 2001 (2001) diz que "os conteúdos dos programas devem desenvolver habilidades básicas (estes devem ter uma abordagem transversal, permeando toda a formação: direitos humanos, cidadania, ecologia, saúde e segurança no trabalho), específicas e habilidades de gestão."

Desta forma, observamos que o PLANFOR foi mais efetivo na transmissão dos conhecimentos diretamente relacionados ao trabalho e à autoestima, mas não pareceu muito eficiente na transmissão de conhecimentos das temáticas curriculares transversais, relacionadas mais diretamente aos valores sociais e políticos gerais da formação dos cidadãos. 


\section{Referências bibliográficas}

ABRANCHES, Sergio Henrique; COIMBRA, Marcos Antonio; SANTOS, Wanderley Guilherme. Política social e combate à pobreza. 2. ed. Rio de Janeiro: Jorge Zahar Editor, 1989.

BARDIN, Laurence. Análise do conteúdo. Tradução de Luís Antero Reto e Augusto Pinheiro. Lisboa: Edições 70, 1994.

CABRAL, Luiz Antonio Palmeira. Planos de desenvolvimento de Alagoas 19602000. Maceió: EDUFAL: SEPLAN-AL: Fundação Manoel Lisboa, 2005.

CAMARGO, Célia Reis (Org.). Experiencias inovadoras de educação profissional: memória em construção de experiências inovadoras na qualificação do trabalhador (1996-1999). São Paulo; Editora UNESP: Brasília: Flacso, 2002.

CORDÃO, Francisco Aparecido. A LDB e a Nova Educação Profissional. Boletim Técnico do Senac, Rio de Janeiro, v.28, n.1, jan. 2002.

CUNHA, Luiz Antonio. Ensino Médio e ensino técnico na América Latina. Cadernos de Pesquisa, \{S.I.], n.3, 47-70, dez. 2000.

DELUIZ, Neise. Formação do trabalhador: produtividade e cidadania. Rio de Janeiro: Shape, 1995.

- O modelo das competências profissionais no mundo de trabalho na educação: implicações para o currículo. Boletim Técnico do Senac, Rio de Janeiro, v.27.n.3, set/dez 2001.

. Formação Profissional no Brasil: enfoques e perspectivas. Boletim Técnico do Senac, [S.I.], v.19:34-44, jan./abr.1994.

. Formação, ou qualificação, ou competência. Veritas, Porto Alegre, v 38 n.149, mar, p. 95-103, 1993.

. Formação \& trabalho \& competência. Porto alegre: edipucrs.1998.

FRIGOTTO, Gaudêncio (Org.). Educação e crise do trabalho: perspectivas de final de século. Petrópolis: Vozes, 1998.

. A Produtividade da escola improdutiva: um (re) exame das relações entre educação e estrutura econômica-social e capitalista. São Paulo: Cortez: Autores Associados, 1984.

KUENZER, Acácia Zeneida. Ensino médio e profissional: as políticas do Estado neoliberal. São Paulo: Cortez, 1997. 
LAURELL, Asa Cristina (Org.). Estado e políticas sociais no neoliberalismo. In: Revista técnica de Amélia Cohn. Tradução de Rodrigo Leon Contrera. 2. ed. São Paulo: Cortez, 1997.

MACHADO.Lúcia Regina de Souza. O modelo de competências e a regulamentação da base curricular nacional e de organização do Ensino Médio. Revista do NETE, Belo Horizonte, n.4, ago/dez, 1998.

MANFREDI, Silvia Maria. Educação profissional no Brasil. São Paulo: Cortez, 2002.

MARTINS, Marcos Francisco. Ensino técnico e globalização: cidadania ou submissão?- Campinas: Autores Associados, 2000 (coleção polêmicas do nosso tempo:71).

OLIVEIRA, Marco Antonio (Org.). Reforma do Estado e políticas de emprego no Brasil.Campinas (SP): UNICAMP, IE, 1998.

OLIVEIRA. Ramom. Empregabilidade e competência: conceitos novos sustentando velhos interesses. Revista Trabalho e Educação, Belo Horizonte, n. 5, Jan/Jun. 1999.

PIZZI, C. V. As transformações produtivas e os desafios às propostas pedagógicas progressistas nos anos 90. Educação: Revista do Centro de Educação da UFAL, Maceió, v. 14, p. 17-31, julho, 2001.

.Análise de conteúdo e análise do discurso nas pesquisas do currículo.XVII EPENN, Belém, jun. 2005.

QUEIROZ, Delcele Mascarenhas. Qualificação e Educação. Boletim Técnico do Senac, [s.I.], v.20:26-32,jan/abr.1994.

RAMOS, Marise Nogueira. A pedagogia das competências: autonomia ou adaptação? São Paulo: Cortez, 2001.

SANTOS, Lucília L. C. P. Um currículo para a escola cidadã. Seminário Internacional sobre Reestruturação Curricular. Porto Alegre, SEMED, julh. 1994.

SANTOS. Oder José dos. Novo mundo do trabalho, nova pedagogia capitalista. Trabalho e Educação. Revista do NETE, Belo Horizonte, n.2, ago/dez 1997

SCHWARTZMAN, Simon. As causas da pobreza. Rio de Janeiro; Editora FGV, 2004.

TEM/SPPE/DEQP. Guia do PLANFOR 2001. Brasília, 2001. (versão revista). 
TRIVIÑOS, Augusto. Introdução à pesquisa em Ciências sociais.São Paulo: Atlas, 1987.

\footnotetext{
${ }^{1}$ Doutora e Professora da Universidade Federal de Alagoas. E-mail:Icvp@fapeal.br

${ }^{2}$ O PLANFOR foi substituído pelo PNQ a partir do ano de 2003, na gestão do Presidente Lula

Nota dos Editores: enviado em 14/04/2008. Aprovado em 15/05/2008.
} 